\title{
The innovative strategy of social and economic development of mining region
}

\author{
Sergey Bereznev ${ }^{1 *}$, Olga Zonova $^{2}$, and Elmira Lubkova ${ }^{2}$ \\ ${ }^{1}$ T. F. Gorbachev Kuzbass State Technical University, Production Management Department, 650000 \\ Kemerovo, 28 Vesennya st., Russian Federation \\ ${ }^{2}$ T. F. Gorbachev Kuzbass State Technical University, Finance and credit Department, 650000 \\ Kemerovo, 28 Vesennya st., Russian Federation
}

\begin{abstract}
Depressed state of Russian economy in recent years, the unstable functioning of most regional social and economic systems in the conditions of increased uncertainty of the global economy makes strategizing of the development based on a new model of economic growth a highly important issue. It assumes the tasks of modernization and restructuring of the economy, as well as improving the quality of management. It is known that the solution of these conceptual target problems was suggested by the concept 2020 , but the global crisis of 2007 2009 and other geopolitical factors in the post-crisis period pushed their implementation back. The results of 2016 show an adaptation of Russian economy to the difficult internal and external challenges. In this article, the authors analyze the strategizing process by the example of the "Strategy of social and economic development of the Kemerovo Region up to 2025", as well as analysis comparatively the strategies for the development of the national economy, the Siberian Federal District and the region. Based on the study results the authors formulated and substantiated conclusions and recommendations to improve strategizing process and the effectiveness of strategic management of the development of social and economic systems.
\end{abstract}

\section{Introduction}

The main legal acts regulating the procedure of the formation and content of documents for economic development strategizing of the national economy and regional social and economic systems of the Russian Federation subjects include the following: the federal laws "On state forecasting and programs of social and economic development of Russia» № 115-FZ on 20.07.1995 (rev. on 09.07.1999) and "On the strategic planning in the Russian Federation» № 172-FZ of 28.06.2014, as well as the Concept of long-term social and economic development of the Russian Federation for the period till 2020, technical standard "The requirements for social and economic development of the Russian Federation subject" and the regional laws.

The federal law №115-FZ and the corresponding legal acts provide for the following stages for strategizing: 1) the forecasting of social and economic development of the

\footnotetext{
*Corresponding author: bereznev45@mail.ru
} 
administrative and territorial unit in the long and medium term; 2) concept formulation of the social and economic development in the long term based on the previous forecast; 3 ) designing the program of social and economic development in the medium and long term (in order to ensure the continuity of economic and social policy of the state). Later, the federal law №172-FZ made some amendments concerning the preparation order and content of the documents, according to which the regional law of the Kemerovo region "On strategic planning" №103-OZ of 23.12.2016 was adopted.

\section{Methods}

The development methodology for the strategy of social and economic development is based on the combination of two approaches: 1) economic-and-mathematical approach [1], involving the collection, processing and analysis of objective and subjective indicators (statistical data and data obtained from interviews) characterizing the social and economic development of the administrative-territorial unit; 2) scenario approach [2], involving an analysis of possible deviations from the targets of the administrative-territorial unit development and defining the activities aimed at implementing the most favorable for the regional development scenario and leveling the risk events which may impede the realization of a particular scenario.

In foreign and domestic theory and practice the opinion about the content of the main components of the strategizing system is considered to be well established: 1) the business model of the region (the subject of the Russian Federation), which reproduces the dynamics of social and economic processes; 2) the system of strategic management forming and working out the administrative decisions on the model of the region; 3) economic agents in the model as an interactive set of economic activities (in accordance with the division on the national Classification of Economic Activities); 4) households and the agent "invisible hand of the market", responsible for the balance of supply and demand in the markets of goods and factors of production [3, 4].

\section{Results and Discussion}

The analysis of currently implemented "Strategy of social and economic development of the Kemerovo Region up to 2025" approved by the Kemerovo region law № 74-OZ on 11.07.2008 (amended on 02.11.2012) revealed the following: 1) strategy of social and economic development of the Kemerovo region is basically consistent with the objectives of the "Concept of social and economic development of the Russian Federation until 2020" and the "Energy strategy of Russia until 2020", as well as with the priorities of the "Strategy of long-term social and economic development of Siberia until 2020"; 2) policymakers made SWOT-analysis and used scenario approach to justify the selection of the target (active) scenario of strategic development; 3) the purpose of the strategic development till 2020 was the following: "the increase of the regional competitiveness and population wellbeing growth on this basis". However, it should be noted that the strategic goal, first of all, is not linked with the mission of social and economic development of the region; 4) the program block of the strategy provided a number of tasks the solution of which implied the achievement of the strategic development target.

As it follows from the mentioned above the developers complied with the basic formal characteristics and rules for the development of regional development strategy, including the coordination of regional target with Siberia development priorities.

However, the choice of the so-called active scenario, which, in fact, implies the change of the technological layer, coincided with the period of the global financial and economic 
crisis of 2007-2009. During this period, even without taking into account the challenges and risks generated by the global crisis, the list in the SWOT-analysis of existing restrictions for the development of regional social and economic system in depth, nature and scale of problems is actually institutional conglomeration of factors (capital, labor, management and etc.), which has the highest inertia. It is not only the problems and peculiarities of the natural resource region, but also the problem of Russian national economy as a whole, which complicates the solution of strategic tasks in the context of subsidiary relationship between the RF subject and the federal authorities in tax revenue distribution. It is known that now there is a sharp imbalance of tax revenues in favor of the federal budget. So from 1 ruble which generates a large investment project, 85 kopecks go to the federal budget, only 14 kopecks to the regional one, and, accordingly, 1 kopeck to the municipality. It is obvious that such situation and chronic imbalance in the regional budget does not increase investors' confidence and reduces the possibility of regional authorities in cooperation with the business within public-private partnership.

Another aspect in our opinion deserves deeper assessment and consideration in the implementation of tasks to achieve the goal of "active" scenario. It is an issue of resources and, in particular, about own financial possibilities of regional businesses. As the experience of previous years showed funding of short and medium term investment programs in the real sector of the Kemerovo region was provided by business on $80 \%$ from its own profit. In the pre-crisis period production assets indicators and profitability of basic industries actually reached their limits by market conditions. During these years, there was a favorable situation on foreign markets for the export group of products (coal, metal, fertilizer) the highest saving rate of about $30 \%$ of the GRP was achieved [5]. During the development and adoption of the strategy the world economy, especially the markets of energy products, showed clear signals of reducing conditions and therefore there was no possibility to rely on the former exporting model by the developers. Moreover, the enlarged assessment of funding necessary to solve the strategic tasks with a planning horizon up to 2025 made by the authors showed that the rate of accumulation had to be increased up to $50-60 \%$, which is unrealistic in a post-crisis economy and long-term external challenges.

Unfortunately, the forecast quality, the assessment of the resource base and the attainability of chosen scenario, its target, is considered to be one of the "narrow" places in the national practice of strategizing social and economic development. We believe that these shortcomings are fully applicable to the development strategy of the Kemerovo region. The limits of this article does not allow talking about these and other aspects of the strategizing process, however, we should note one more fundamental observation which follows from the analysis: "wellbeing growth" of the population in the region is, of course, a good and dominant purpose of the whole philosophy of the social and economic development. This is an internationally recognized value which is directly connected with other criteria and indicators: quality of life, life expectancy, population reproduction, etc. $[6,7]$. The social and economic sphere of the Kemerovo region has its own specific characteristics: the dangerous production, multi-shift mode of employed in basic industries and as a consequence of these and other conditions - low average life expectancy (68 years which is below the national average level on almost 3 years). Kemerovo region, one of the few industrial regions, which does not provide a simple reproduction of the population and shows the trend of steady decrease in total population (2006-2016 on 88,314 people) and a very high occupational diseases. These are real internal challenges, which do not only find a proper solution in the scenario of coal mining expansion, but also form a vicious circle. According to the Institute of coal and coal-chemistry of RAS, increased coal production by 10 million ton per year will increase by $1 \%$ the incidence rate in the Kemerovo region, which entails the growth of budget expenditures on health care and the implementation of environmental protection measures. That is why we consider that one of the main 
requirements for strategy development should become not formal but thorough and in-depth implementation of the correlation of the interests of authorities, economic agents and society.

In 2012, the strategy of social and economic development of the Kemerovo region, taking into account internal and external challenges was adjusted, and its goal was not changed. What are the reasons for making adjustments in the strategy? Let us refer to the workbook of the "Strategy of social and economic development of the Kemerovo region", posted on the Kemerovo region Administration website. It proves the necessity of adjustments: risks faced by the implementation of the strategy and the emergence of new economic growth drivers.

Special attention deserves the strategic statement "the development of coal industry". Thus, the increase of coal industry role in the national fuel and power complex and Russian economy as a whole is projected. The growth of domestic demand and export potential of the Asia-Pacific region markets stipulate the necessities of increasing the competitiveness of industry. An interesting fact is that the economic development strategies, adopted at the federal level, do not set a goal to increase coal exports, which cannot be said about the strategic documents of the Kemerovo region. According to the mentioned above, we believe that the regional "development" must still have parametric environmental restrictions in accordance with the principles of the Concept of Sustainable Development of the United Nations organization [8].

\section{Conclusion}

The analysis of strategizing of social and economic development of the region revealed a number of "narrow" places, leveling which will lead the development of strategic documents to a new level. The authors are aware that it becomes difficult to predict the future [15]. Perhaps the way out of this situation would be timely and systematic monitoring of the strategy implementation. It is surprising that after understanding (in 2011) that the strategic target of social and economic development of the Kemerovo region is unreachable, neither target nor scenario was changed. In our view, the most appropriate at the present time would be the implementation of the transition scenario, aimed at the effective interference of raw material and innovative model of development of the regional economy.

\section{References}

1. L.V. Kantorovich, Manag. Sci., 6, 4 (1960)

2. K. Riahi, A. Grübler, N. Nakicenovic, Technol Forecase Soc, 74, 7 (2007)

3. V.K. Mathur, Econ. Dev. Q., 13, 3 (1999)

4. A. Lagendijk, J. Cornford, Geoforum, 31, 2 (2000)

5. S. Bereznev, M. Kumaneeva, M. Makin, 8th Russian-Chinese Symposium. Coal in the 21st Century: Mining, Processing and Safety (Atlantis Press, 2016)

6. O. Zonova, E. Nekhoda, E. Slesarenko, 8th Russian-Chinese Symposium. Coal in the 21st Century: Mining, Processing and Safety (Atlantis Press, 2016)

7. E. Vershkova, T. Filippova, E. Nekhoda, SHS Web of Conferences, 28 (2016)

8. J. Friedmann, M. Douglass, Agropolitan development: towards a new strategy for regional planning in Asia (United Nations Centre for Regional Development, Nagoya, 1976) 